\title{
EFFECT OF BIRD DENSITY ON THE DECISION TO JOIN A GROUP IN THE SICALIS FLAVEOLA PELZENI (PASSERIFORMES, EMBERIZIDAE)
}

\author{
Celia M. Lombardi ${ }^{1}$ \\ Marcela Charbuki
}

\begin{abstract}
A change in bird density within a captive flock of Sicalis flaveola pelzeni (Sclater, 1872) affected the decision to join a group. Ruling out inter-individual differences and maintaining constant the size of a food patch, birds were found to fly more often to the food source and spend a longer time in its environs when kept in greater groups.
\end{abstract}

KEYWORDS. Sicalis, social behavior, bird density.

\section{INTRODUCTION}

Individuals of many animal species are called social because they are frequently found in groups. Their behavior seems to be readily influenced by the behavior of conspecifics (CLAYTON, 1978). Visual as much as auditive cues may influence the decision to join a group. Social learning, when referred to learning from others where and what to feed is known as local and stimulus enhancement (KrebS, 1973; Heyes, 1994). Studying the great blue heron (Ardea herodias Linnaeus, 1758) KREBS (1974) found that free ranging birds were more attracted by a group of five styrofoam models than by a single one. The results suggest that each bird in a group would appear to represent a separate stimulus. One could then speculate about the incidence of a summation effect; i.e., a greater density of birds would intensify the attraction property of a group.

Saffron finches are small $(12 \mathrm{~cm})$ social birds. Adults are sexually dimorphic and both parents help to raise the young (MARCONDES-MACHADO, 1988). They are mainly monogamous, but some cases of polygyny were observed (BUSCHINELLI, 1971; MARCONDESMACHADO, 1982). Explicit aggression is rare among juveniles and interactions are limited to light threats and small hops that make the nearest neighbor move aside (MARCONDESMACHADO, 1997). Here are presented results of experiments on captive saffron finches (Sicalis flaveola pelzeni Sclater, 1872) intended to evaluate whether birds equally matched in ability and motivation would modify their choice (staying on a perch or

1. Museo Argentino de Ciencias Naturales, Av. Angel Gallardo 470, 1405 Buenos Aires, Argentina. (CONICET).

2. Departamento de Biología, Universidad de Buenos Aires, Pabellón II, 1428 Buenos Aires, Argentina. 
flying to the ground to join a group) according to bird density, when presented with a highly localized food patch of constant size. It was hypothesized that if the decision to join a group were indeed socially influenced, a greater bird density would result in a greater amount of time spent on the ground with the group and a greater number of flights to the ground.

\section{MATERIAL AND METHODS}

Twenty eight captured wild saffron finches were used, purchased from commercial suppliers. They were identified by color leg bands. To minimize the influence of sexual and phenotypical variations on aggressiveness, only juveniles of unknown sex and age were used. It was assumed they were approximately matched in ability. They were maintained in groups of four individuals in side-by-side placed cages $(80 \times 80$ $\mathrm{x} 40 \mathrm{~cm}$ ), in full view of neighboring cages. They received natural light and were freely supplied with a mixture of grains, vegetables, fruits, water and sand. Cages contained perches but no nests.

During experimental sessions a screen separated the set-up from the housing cages. The set-up consisted of an aviary $(1.4 \times 1.5 \times 1.8 \mathrm{~m})$ equipped with perches and placed between a window and the screen. The window allowed a free view of the surrounding countryside, an important factor influencing responses specially when birds are caged (LOMBARDI \& CURIO, 1985). An opening in the screen allowed the observer to collect data. Before starting each session the aviary floor was covered with sheets of paper and the habitual trays of food removed. Two wood sticks were placed crosswise on the floor dividing it into four equal quadrants, one of them thereafter called "food plane", with a tray $(15 \times 10 \times 5 \mathrm{~cm})$ containing about $200 \mathrm{ml}$ of millet. The same food plane was used in all sessions. Water was supplied in four standard cylindrical devices, placed at each corner of the aviary floor.

The experiment involved two test conditions (treatment levels), one with a low density of individuals and the other with a high density. Each condition comprised 14 sessions (replicates). Half of the subjects performed first under the low condition and subsequently under the high condition. The remaining half performed inversely. Birds were allocated at random on each level. Each experimental subject was tested under both treatment levels. Sessions were run during the morning, about twice a week. At the beginning of each session the experimental pair of birds was placed in the aviary and remained there throughout the session. Companion birds were added later, at the beginning of the third step.

A session consisted of four steps (tab. I). The first and the third steps lasted $30 \mathrm{~min}$ each and no behavioral records were made. The first $15 \mathrm{~min}$ of these steps were run with the food tray in place, to get the birds (the experimental ones in the first step and the companion ones in the third step) habituated to the setup. The remaining $15 \mathrm{~min}$ were run without food in order to have all the birds with the same degree of motivation, since they were supplied with food ad libitum before sessions.

Data were collected during the second and the fourth steps. These were run with the food tray placed in the middle of the food plane. The second step served as a baseline (covariate); it lasted $10 \mathrm{~min}$ and the

fourth step (criterion) lasted $20 \mathrm{~min}$. The same two experimental subjects were measured during both

Table I. Representation of the four steps involved in a session. Behavioral records of Sicalis flaveola pelzeni were taken only during the baseline and criterion steps, which lasted ten and twenty min respectively.

\begin{tabular}{lllll}
\hline $\begin{array}{l}\text { Step } \\
\text { Order }\end{array}$ & $\begin{array}{l}\text { Step } \\
\text { Duration } \\
(\mathrm{min})\end{array}$ & $\begin{array}{l}\text { Food tray } \\
\text { Present }\end{array}$ & $\begin{array}{l}\text { Behavioral } \\
\text { Records }\end{array}$ & $\begin{array}{l}\text { Step } \\
\text { Label }\end{array}$ \\
\hline 15 & Yes & No & Habituation \\
\hline 2 & 15 & No & Yes & Baseline \\
\hline 3 & 10 & Yes & No & Habituation \\
\hline 4 & 15 & Yes & & Criterion \\
\hline
\end{tabular}
steps. After the baseline, the food tray was replenished and two more birds (companions) were added to the aviary in the low density test condition and twelve more in the high density test condition. Behavioral records were taken only on experimental subjects (not on companions), both separately. The choice of using two experimental birds per session instead of one, was to avoid the confounding influence of the stress induced by social isolation (during the baseline), a well known effect in social organisms.

The attraction to the food source was measured by recording the number of flights to the food plane and the time each visit lasted. The total surface of the food plane was considered, instead of only the food tray, for two reasons. Firstly, the perimeter of the food tray (tailored to species-specific 
inter-individual distance) allowed only two birds feeding at the same time. Flight number and duration only at the food tray may thus have represented, though by design minimized, individual differences in competitive abilities. Secondly, spillage produced by birds at the food tray made seeds spread in all directions and most birds fed on them or simply pecked at unknown stimuli.

Statistical analysis were done with BMDP (Dixon, 1992). Raw data were transformed to $\ln (\mathrm{Y}+1)$ since they were not normally distributed. Each of both dependent variables, the number of visits to the food plane and the time spent on it (in min), were averaged for both experimental subjects (i.e., both subjects yielded one datum point) to avoid pseudoreplication (Hurlbert, 1984; LOMBARDi \& HuRLBerT, 1996). The analysis of covariance (one for each dependent variable) were done considering the baseline as a covariate changing across trials. Covariates and criterion measurements for treatment levels were regarded as paired data. Mean time spent on the food plane and mean number of flights were calculated as mean duration and frequency respectively. The total recorded time a experimental bird was on the ground throughout a session, or the total number of flights, divided by the units of time (min) a session lasted. Confidence intervals on the difference between means (adjusted to baseline) from matched pairs were calculated on the transformed data and then retransformed into natural antilogarithms (DAMON \& HARVEY, 1987).

\section{RESULTS AND DISCUSSION}

Both number of flights to the food source and time spent around it were markedly influenced by bird density (covariance analysis yielded $\mathrm{F} 1,12=7.31 \mathrm{P}<0.02$ and $\mathrm{F} 1,12$ $=14.21 \mathrm{P}<0.01$ respectively, figs. 1, 2). During low bird density test condition, mean values of the averaged number of flights (per min) were 0.06 for the baseline (two birds) and 0.08 for the criterion step (four birds). On the high density condition, the means were 0.05 (two birds) and 0.15 (14 birds). The time spent on the food plane showed the same trend. Means (per min) were 0.03 and 0.05 (two and four birds respectively during the low density condition) and 0.02 and 0.14 (two and 14 birds in the high density condition).

It was clearly shown that an increase in bird density elicits a greater number of flights to the ground and a longer time spent on it, as otherwise experimental birds prefer to remain on the perch. Inter-individual differential competitive abilities could not account for the results. Individuals served as their own control because a paired data design was used, and the experimental unit was an average of the measurements of two birds. Since it was used a design of the before-after type, intra-individual variations due to the passage of time were adjusted using the baseline as a covariate. It was controlled for both intraand inter-individual variations, so neither could account for the results. The possibility exists, that the pair of experimental birds showed territorial behavior, since they were placed in the aviary $40 \mathrm{~min}$ before their companions. Whether juveniles can develop such behavior in a relatively short period of time seems unlikely (MARCONDES-MACHADO, 1997). If such were the case, it fails to explain why they should be differentially territorial at each density level. Another alternative explanation would be food depletion. Since the food tray was not replenished during the $20 \mathrm{~min}$ the criterion step lasted, food depletion may have elicited competition. As two hours of gradual depletion has failed to lengthen the time spent on the food plane in a pilot experiment, this explanation is hardly tenable.

Many theoretical and empirical studies have shown the advantages of joining a flock (Krebs \& Davies, 1978; Caraco, 1979; Clark \& Mangel, 1984) though related with the optimal foraging paradigm, i.e, offering two food sources simultaneously. A greater protection against predators and less time a bird has to spend searching for food itself are the related main explanations. Studying flocking decisions related to food availability in free ranging sparrows, ElgaR (1987) found that birds preferred to join a flock rather than to forage alone, irrespective of food source size and in spite of reduced intake rate as a result of 


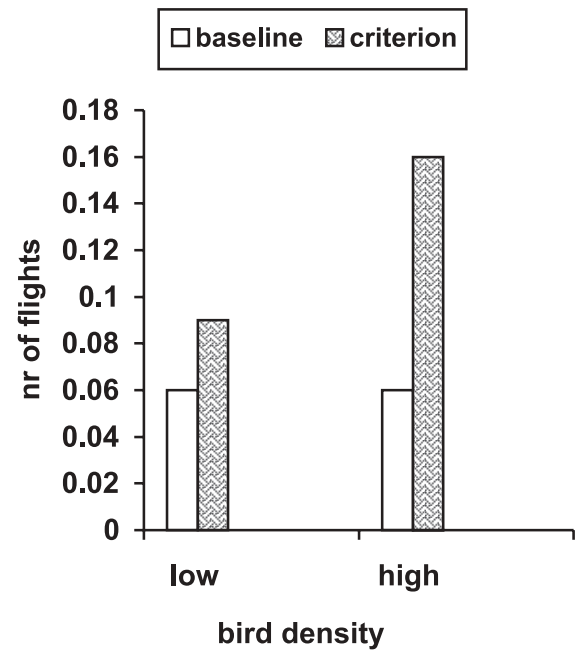

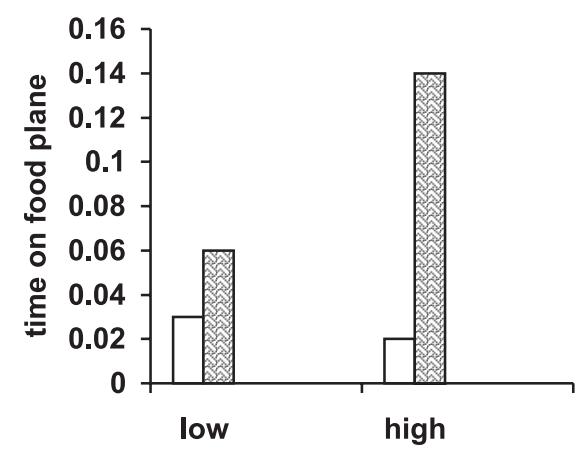

bird density

Figs. 1, 2. 1, mean number of flights of Sicalis flaveola pelzeni (per min, raw data) to the food plane averaged for both experimental subjects under the low and high density treatment levels during the $2^{\text {nd }}$ ( $\square$, baseline) and the $4^{\text {th }}$ ( , criterion) step. The difference between unadjusted criterion means was 0.06 . The $95 \%$ confidence interval for the adjusted difference ranged from 1 to 1.08. 2, mean time spent on the food plane (per min, raw data) averaged for both experimental subjects under the low and high density treatment levels on the $2^{\text {nd }}$ (baseline) and the $4^{\text {th }}$ (criterion) step. The difference between unadjusted criterion means was 0.08 . The $95 \%$ confidence interval for the adjusted difference ranged from 1 to 1.06 .

greater flock size. Though in a different way and situation, his results were herein confirmed. Quite likely, greater protection against predators and less time a bird has to spend searching for food itself are the main explanations for the observed effect.

Acknowledgments. To M. Gandini for writing the computer program to record bird behavior. To C. Herrera (Univ. Nac. del Comahue) and S. Hurlbert (San Diego State University) for comments on the manuscript. To two anonymous reviewers and to the editorial board of Iheringia for helpful suggestions.

\section{REFERENCES}

Buschinelli, A. 1971. Contribuição ao estudo da biologia do canário da terra. Ciênc. Cult., São Paulo, 23 (2): $163-166$.

CARACo, T. 1979. Time budgeting and group size: a test of theory. Ecology, New York, 60:618-627.

Clark, C. W. \& Mangel, M. 1984. Foraging and flocking strategies: information in an uncertain environment. Am. Nat., Chicago, 123:626-641.

Clayton, D. A. 1978. Socially facilitated behavior. Q. Rev. Biol., London, 53:373-392.

DAMON, R. A. \&. HARVEY, W. R. 1987. Experimental design, ANOVA, and regression. New York, Harper \& Row. 508 p.

Dixon, W. J. 1992. BMDP Statistical Software Manual. Berkeley, Univ. of California. 1500 p.

Elgar, M. A. 1987. Food intake rate and resource availability: flocking decisions in House Sparrows. Anim. Behav., Cambridge, 35:1168-1176.

Heyes, C. M. 1994. Social learning in animals: categories and mechanisms. Biol. Rev., London, 69:207-231.

Hurlbert, S. H. 1984. Pseudoreplication and the design of ecological field experiments. Ecol. Monogr., New York, 54:187-211.

KREBS, J. R. 1973. Social learning and the significance of mixed-species flocks of chickadees (Parus spp.). 
Can. J. Zool., Toronto, 51:1275-1288.

. 1974. Colonial nesting and social feeding as strategies for exploiting food resources in the great blue heron (Ardea Herodias). Behaviour, Leiden, 51:99-134.

Krebs, J. R. \& Davies, N. B. 1978. Behavioural ecology. Oxford, Blackwell Scientific. 494 p.

Lombardi, C. M. \& Curio, E. 1985. Influence of environment on mobbing by Zebra Finches. Bird Behav., New York, 6:28-33.

Lombardi, C. M. \&. Hurlbert, S. H. 1996. Sunfish cognition and pseudoreplication. Anim. Behav., Cambridge, 52:419-422.

Marcondes-Machado, L. O. 1982. Poliginia em Sicalis flaveola brasiliensis (Gmelin, 1789) (Passeriformes, Emberizidae). Revta bras. Zool., Curitiba, 1 (1):95-99.

- 1988. Divisão de trabalho em cuidados à prole em Sicalis flaveola (Linnaeus, 1766) (Passeriformes, Emberizidae), em cativeiro. Revta bras. Zool., Curitiba, 5 (2):201-208.

- 1997. Comportamento social de Sicalis flaveola brasiliensis em cativeiro (Passeriformes, Emberizidae).

Iheringia, Sér. Zool., Porto Alegre, (82):151-158. 